\title{
Modeling of factors affecting investment behavior during the pandemic: a grey-DEMATEL approach
}

\author{
Ritika $^{1} \cdot$ Himanshu $^{2,3}$ (]) Nawal Kishor ${ }^{1}$
}

Received: 14 July 2021 / Revised: 25 January 2022 / Accepted: 26 January 2022

(c) The Author(s), under exclusive licence to Springer Nature Limited 2022

\begin{abstract}
The study intends to examine the cause-and-effect relationship between Covid-19 and the factors affecting investment behavior in a South Asian economy. The investment behavior is considered as an MCDM problem. To address this problem, the study employs MCDM approach i.e., a blend of both DEMATEL and Grey theory due to its potential to deal with subjective judgments of investors. The results indicate that Covid-19 is the leading cause behind financial stress, psychophysiological health outcomes, investors' perception about the market, and investors' strategy. Among sub-factors, portfolio allocation is the most influenced sub-factor. Alteration in portfolio is a major challenge for emerging countries which have become attractive destinations for global investors. Overall, the significant contribution of the paper is to establish the interlinkages among the factors affecting investment behavior, given the uncertainty triggered by the pandemic. Although the literature provides evidence on this problem during normal situations, analysis of investment behavior during severe crisis is still lacking. The research will be immensely useful to different stakeholders such as government, policymakers, financial advisors, and investors in making their strategic or operational decisions.
\end{abstract}

Keywords Decision-making $\cdot$ Investment behavior $\cdot$ Pandemic $\cdot$ Portfolio allocation $\cdot$ Volatility

\section{Introduction}

World Health Organization declared Covid-19, a global pandemic on March 11, 2020 (WHO, 2020). The devastating and disruptive impact of Covid-19 on various economies of the world have started emerging. Covid-19 has induced a financial crisis worldwide. The devastating and disruptive impact of Covid-19 on various economies of the world has started emerging. The fear and uncertainty arising from Covid-19 have sent the major financial markets to crashes at levels higher than those witnessed during the global financial crisis of 2008. The stock markets in the world experienced

Himanshu

himanshu@bm.iitr.ac.in

Ritika

ritikaaneja.aneja@gmail.com

Nawal Kishor

Nkishor@ignou.ac.in

1 School of Management Studies, IGNOU, New Delhi, India

2 Indian Institute of Technology, Roorkee, India

3 DRA Govt. Degree College, Bisauli, India sharp volatility during such crisis. The change in trends and indices of the stock market due to Covid-19 have indicated the gloomy sentiments of the domestic and foreign investors. The developing economies in Asia have played an important role in curtailing the repercussions of the financial crisis (Fjellstrom et al., 2019). During the last few decades, the emerging financial markets of Asian economies have manifested themselves to be the initiators of change throughout the world (Singh and Gaur, 2020).

To make our case, we take India, an emerging economy, as an example. Prior research states that India has the potential to transfigure the worldwide economy in the twenty-first century (Engardio, 2006; Jalan, 2011). In India, the Nifty 50 and BSE Sensex correlated to the global markets, declined by $22.6 \%$ during the first wave of Covid-19 (Covid 1.0) period (Mishra et al., 2020). India adopted a strict lockdown, thus impacting economic activities. The country reported a negative GDP of $23.1 \%$ in the first quarter (Q1) of FY 2020-21 (Ministry of Statistics and Programme Implementation, 2020), then GDP contracted by $7.5 \%$ in Q2, indicating a V-shaped recovery and increased by $0.5 \%$ in Q3. For FY 2021-22, the government estimated real GDP to be $11 \%$. Specifically, the growth rate was negative for manufacturing 
and service sectors (The Economic Survey, 2021). This had adversely affected the investors' perceptions to invest in such sectors. Furthermore, the revised estimate of fiscal deficit soared by three times. The mounting fiscal deficit diverted the capital from investment to borrowings for covering up the deficit. Due to a strict lockdown, the unemployment rate in India peaked at a level of $26 \%$ in April 2020, leading to a loss of around 120 million jobs during April (Vyas, 2020). Firms have reduced production and laid off many employees. Although the unemployment level changed after the easing of lockdown restrictions, it was still around 8.4\% in August 2020 (Sharma, 2020). Covid-19 has also laid an unfavorable impact on the income of people. $63 \%$ of Indians reported losses in their income due to the pandemic because the revival in employment was not matched with an equivalent change in income (India Today, 2020). The income of people remained lower as compared to the prepandemic period. People were forced to cut back on buying even the essential items. Lower income has also discouraged them from making further investments (Ghosh, 2020). Thus, investment uncertainty has severely hit the economic growth of the country.

Recently, India is witnessing catastrophic second wave of Covid-19 (Covid 2.0), even the vaccination drive has started. There is a sharp surge in covid new cases which have crossed whopping of 3 lakhs. Although the state governments have uneased restrictions after the first phase, they have now started imposing lockdowns again to tackle Covid 2.0. Total loss to the economy is still unpredictable. The World Bank projects downward estimate of real GDP growth at $10 \%$ as against $11 \%$ in economic survey. The BSE Sensex has tumbled by more than 4000 points after reaching a record high of nearly 52,000 in February (Mudgill, 2021). Covid 2.0 has spooked domestic and foreign investors and provoked them to sell off their holdings which is hardly hitting mid and small cap stocks.

In the present context, it is significant to comprehend the consequences of a negative shock like Covid-19 for investors because investors react rapidly to negative news by intensifying their information search (Dzielinski, 2012). Due to the enormous information received by investors during a crisis, their perceptions change frequently, and a large divergence is also experienced in their perceptions (Glaser and Weber, 2005). This frequent transformation and divergence in the perceptions induce higher trading among the investors, where the transformation inspires trade, and differentiation prompts herding behavior (Harris and Raviv, 1993). When the crisis is at its peak, the risk tolerance and return expectations of the investors start diminishing (Hoffmann et al., 2013). So, the extent of disfigurement due to any negative macro-economic experience depends on the conceptions and reactions of the investors. Thus, the analysis of investment behavior is necessary to have a comprehensive understanding of the impact of rare events on the financial and economic systems in emerging economies.

Although various studies aimed at gauging the extent of the contagion effect of the crisis in the on financial markets in emerging economies (Al-Awadhi et al., 2020), there are limited studies to analyze the primary psychological mechanism leading to such a considerable contagion effect produced by the crisis. Even though it is believed that the contagion effect is the result of activities undertaken by the investors, the conditions leading them to behave in such a manner is still understudied. This study aims to fill this gap. So, the present study looks at it from the angle of the financial crisis produced by the Covid-19 pandemic. The paper intends to analyze the effect of the Covid-19 pandemic on investment behavior. Specifically, the paper examines the cause-and-effect relationship among the factors affecting the investment behavior during the pandemic.

There exists a disagreement on the effect of financial crisis on the behavior of investors (investors' expectations and inclination toward investments in stock markets). Theories of traditional finance suggest that investors consider only market fundamentals, and they have stable risk tolerances (Olsen, 2000). But behavioral finance proponents assert that risk tolerances vary with respect to time and macroeconomic experiences have an impact on investors' behavior (Malmendier and Nagel, 2011). Hence, in view of the above arguments, this study investigates the following research questions:

RQ1. What are the factors driving investment behavior during the pandemic?

RQ2. How are the identified factors inter-linked?

RQ3. Which is the most prominent factor that affects investment behavior?

For the purpose of addressing these research questions, interviews with experts and a questionnaire survey were conducted. The grey-DEMATEL technique was employed due to its potential to deal with subjective judgments of investors (Gupta and Barua, 2018; Kumar and Anbanandam, 2020b). The study finds that financial stress, specifically anxiety and depression are the prominent factors affecting investment behavior during the pandemic. The study holds significance as the investors are key players impacting the financial and economic systems.

The major contributions of the study are threefold. First, the study analyzes the effect of the severe Covid-19 pandemic on a complex problem i.e., investment behavior which is considered as an MCDM problem. This problem is less explored during severe crisis in the literature. Second, the application of Grey-DEMATEL in this domain is unique that not only establishes causal relationships among the factors affecting investment behavior, but also quantifies the effect of one factor over other. Lastly, the study has practical 
implications. The study will be immensely useful to the governments and the policymakers while devising the policies for combating the effect of the financial crisis on investors, financial markets, and the economies at large. The research will also be useful to the financial advisors to reduce the impact of emotions on investors' financial decisions. The results can be taken as inputs in the decision-making process by the investors and the policymakers of other Asian economies with similar institutional environments.

The rest of the paper is organized as follows. Section 2 reviews the factors affecting investment behavior during the pandemic. Section 3 discusses research methodology. Section 4 presents the empirical outcomes. Section 5 concludes, followed by implications.

\section{Related literature}

According to the existing literature and expert inputs, the identified factors affecting investment behavior during the pandemic are discussed below.

\section{Covid-19}

Unemployment rates escalate during the pandemic as the demand for employees plunges due to decreased economic demand and growth (Arndt and Lewis, 2001). Unemployment rates for women can be higher due to caregiving responsibilities. For example, during the lockdown, working women have not been able to continue their full-time jobs due to a rise in the share of childcare needs (Alon et al., 2020). Due to financial crisis, people face lot of hardships pertaining to unemployment, job insecurity and change in income (Morin, 2010). Covid-19 has led to unemployment (Nguyen et al., 2021), job insecurity, reduced savings, and increased liquid asset balances (Cox et al., 2020; Qian and Fan, 2020; Haapio et al., 2021).

\section{Investors' perceptions about the market}

Risk perceptions and tolerance of investors are swayed by emotional factors. Prior studies assert that risk tolerance, return expectations, and risk perceptions of investors have been changed due to the catastrophic event in the financial markets (Corter, 2011; Gerrans et al., 2013; Hoffmann et al., 2013). People become less risk-tolerant during and after a financial crisis as fear leads to loss of control and risk aversion (Burns et al., 2012; Ritika and Kishor, 2020). Due to crisis, investment activity is perceived as a riskier activity by the investors (Roszkowski and Davey, 2010; Hoffmann et al., 2013). The expectations of returns are lessened as a response to the financial crisis (Hoffmann et al., 2013).

\section{Financial stress}

Covid-19 represents a fear of unknown events related to global economic and financial systems (Phan and Narayan, 2020). The literature contains evidence of fear that having a negative effect on the performance of stock markets, and some studies accuse media for generating fear (Westerhoff, 2004; Gradinaru, 2014; Badshah et al., 2018; Economou et al., 2018; Narayan, 2019). The spree in the number of infected people and casualties due to COVID-19 pandemic has threatened the livelihood and health of people, thus leading to a perceptible panic among investors (Leduc and Liu, 2020). The fear palpitated due to Covid-19 has resulted in a decline of stock market returns (Al-Awadhi et al., 2020; Salisu and Akanni, 2020). Emerging stock markets like India have also been influenced by the pandemic effect (Topcu and Gulal, 2020).

There is uncertainty about the point at which the devastation caused by Covid-19 would be halted (Phan and Narayan, 2020). Uncertainty about the financial situation increases the perceived risk of the investors (Siegrist et al. 2003, 2005). Perceived risk is heightened by uncertainty, dreadful to contemplate (threatful), and uncontrollable events (Burns et al., 2012). Negative emotions (such as fear, anxiety, distress) have a positive relationship with perceived risk (Lerner and Keltner, 2000).

\section{Psychophysiological health outcomes}

Academic literature mentions that economic downturns deteriorate the personal financial situation, thus adding to psychological turmoil (Stevenson and Wolfers, 2008; Diener et al., 2010; Oquaye et al., 2020; Hasan and Kashif, 2020). Studies report that the worsening financial situation of a person contributes to various psychophysiological health outcomes (psychological distress, depression, and anxiety). The reason being that people take any erosion or destabilization of their financial position very seriously (Brown et al., 2005; Jenkins et al., 2008; Fitch et al., 2011; Rathi and Lee, 2017). They feel worried and anxious as they become unable to achieve their personal goals (Kubzansky et al., 1997).

\section{Investors' strategy}

Every stakeholder tries to minimize the loss caused to them by the financial crisis (Hens and Bachmann, 2008). People use various adaptive strategies to cope up with the effect of the financial crisis (Burns et al., 2012). One such strategy is investors altering their portfolios by allocating less to stocks (Guiso et al., 2018). This change in the portfolio due to the crisis is attributable to regret avoidance, risk aversion, and projection bias (Davis and Madura, 2012; Herberger and Reinle, 2020; Grable et al., 2021). 
During economic uncertainty, investors' sentiments influence volatility and market returns. The pessimism of investors leads to increased volatility (Lee et al., 2002). The dramatic impact of the Covid-19 outbreak on the global financial markets has increased the uncertainty and volatility (Yue et al., 2020; Zhang et al., 2020). The negative GDP, uncertainty, and volatility have led to loss of investors' confidence who responded by changing their risk preferences (Yue et al., 2020).

\section{Data and methodology}

\section{Data collection}

By reviewing the literature and interviewing the experts, five main factors and twelve sub-factors affecting investment behavior were identified. A summary of Covid-19 dimensions and factors affecting investment behavior is provided in Table 1. Initially, a total of eight interviews with experts were conducted to finalize factors. Experts include five academicians having an experience of at least ten years in finance area, and three financial analysts involved in advising investors for a period of more than 15 years.

To examine cause-and-effect relationship between Covid19 and investment behavior, a questionnaire was distributed to 1000 investors in India, of those 780 investors responded, giving a response rate of $78 \%$. They were asked to perform pairwise comparisons among the factors affecting investment behavior during pandemic. Judgment sampling was considered appropriate for selecting the investors. The criteria for selecting the investors were as follows: (a) having an experience of at least five years of investing in financial markets, (b) investments in at least two investment products, (c) knowledge of investment behavior, and (d) they are endowed with the responsibility of making investment decisions in their family, The sample constituted $76 \%$ males and $24 \%$ females which is similar to the studies stating that most of the financial decisions are taken by male members of the family (Ritika and Kishor, 2020; Khawaja and Alharbi, 2021).

\section{Research technique}

In a real-life scenario, analyzing the relationship between Covid-19 and factors affecting investment behavior is a complex task. The investment behavior is considered as an MCDM problem. The study employs the MCDM (Multicriteria decision making) technique to analyze the relationship (Mathew and Sahu, 2018). The major advantage of DEMATEL is that DEMATEL not only indicates prominence, but also ascertains the cause-and-effect relationship among various factors. While, AHP and TOPSIS do not shed light on causal relations (Gupta and Barua, 2018; Kumar and Dixit, 2018; Mathew et al., 2020). Using ANP, a single element cannot be evaluated in isolation for its strengths and weaknesses. So, an increase in the number of elements increases the complexity of the problem in an exponential manner (Wolfslehner et al., 2005). This is not the case with DEMATEL technique as the complex models

Table 1 COVID-19 dimensions and factors affecting investment behavior

\begin{tabular}{|c|c|c|c|}
\hline Main factors & Sub-factors & Code & Related studies \\
\hline \multirow[t]{2}{*}{ Covid-19 (CV) } & Unemployment/employment uncertainty & CV1 & $\begin{array}{l}\text { Arndt and Lewis (2001), Alon et al. (2020), } \\
\text { Nguyen et al. (2021); Expert input }\end{array}$ \\
\hline & Income change (loss of income) & $\mathrm{CV} 2$ & $\begin{array}{l}\text { Cox et al. (2020), Qian and Fan (2020); Expert } \\
\text { input }\end{array}$ \\
\hline \multirow{3}{*}{$\begin{array}{l}\text { Investors' perceptions about market (IP) } \\
\text { (Expert input) }\end{array}$} & Risk tolerance & IP1 & Corter (2011), Ritika and Kishor (2020) \\
\hline & Risk perception & IP2 & $\begin{array}{l}\text { Hoffmann et al. (2013), Ritika and Kishor (2020); } \\
\text { Expert input }\end{array}$ \\
\hline & Return expectation & IP3 & Gerrans et al. (2013), Azimli (2020); Expert input \\
\hline \multirow{2}{*}{$\begin{array}{l}\text { Financial Stress (FS) } \\
\text { (Expert input) }\end{array}$} & Financial uncertainty & FS1 & Burns et al. (2012), Phan and Narayan (2020) \\
\hline & Fear & FS2 & $\begin{array}{l}\text { Ritika and Kishor (2020), Salisu and Akanni } \\
\text { (2020); Expert input }\end{array}$ \\
\hline \multirow{3}{*}{$\begin{array}{l}\text { Psychophysiological health outcomes (PH) } \\
\text { (Expert input) }\end{array}$} & Psychological distress & PH1 & Brown et al. (2005), Jenkins et al. (2008) \\
\hline & Depression & PH2 & $\begin{array}{l}\text { Diener et al. (2010), Stevenson and Wolfers } \\
\text { (2008) }\end{array}$ \\
\hline & Anxiety & PH3 & Kubzansky et al. (1997), Fitch et al. (2011) \\
\hline \multirow[t]{2}{*}{$\begin{array}{l}\text { Investors' strategy (IS) } \\
\text { (Expert input) }\end{array}$} & Portfolio allocation & IS1 & $\begin{array}{l}\text { Expert input; Davis and Madura (2012), Guiso } \\
\text { et al. (2018) }\end{array}$ \\
\hline & Volatility & IS2 & $\begin{array}{l}\text { Expert input; Yue et al. (2020), Zhang et al. } \\
\text { (2020) }\end{array}$ \\
\hline
\end{tabular}


can be easily evaluated using DEMATEL (Gabus and Fontela, 1972; Tseng, 2009; Lin, 2013; Himanshu et al., 2020). The major demerit associated with DEMATEL is that it fails to handle the uncertainty (Seker et al., 2017). Since decision-makers lack access to complete information and mental skills required for taking rational decisions, they usually have vague, ambiguous, and imprecise judgements. Fuzzy set theory helps to solve the problem of uncertainty in decision-making process (Yang and Hung, 2007; Patil and Kant, 2014; Gupta and Barua, 2017). However, grey theory is more suitable for our case study because it does not require large sample size to form appropriate fuzzy relationship function. It does not assume any probability distribution. Thus, it is more effective than fuzzy sets in dealing with uncertainty for data from unknown distribution and small samples (Han et al., 2013; Memon et al., 2015).

\section{Grey system theory}

Grey system theory was propounded by Julong (1989). In real-life scenario, the results may be biased due to ambiguity in human subjective judgments and inadequate information. Grey theory can be utilized to resolve such problems and improve the veracity of judgments of decision-makers (Bhatia and Srivastava, 2018). The theory serves as a basis for greyDEMATEL approach. Recently, the grey-DEMATEL has been employed in various fields such as the effect of COVID on unemployment and supply chains, green innovation, management of sustainable supply chain, freight management, and development of sustainable circular economy (Su et al., 2016; Gupta and Barua, 2018; Kumar and Anbanandam, 2020a; Nguyen et al., 2020; Taqi et al., 2020; Xia and Ruan, 2020). To reap the benefits of both DEMATEL and grey theory, the study employs a blend of both approaches to examine the cause-and-effect relationships among the factors affecting the investment behavior during the pandemic. The causal diagram based on digraphs is formed to show the effect of one indicator on another. The proposed framework of the study is depicted in Fig. 1.

Following prior research (Bhatia and Srivastava, 2018), the steps of Grey-DEMATEL are elucidated below:

Step 1: Let " $n$ " be the number of factors affecting investment behavior during the pandemic, as shown in Fig. 2, and " $m$ " be the number of investors. Initial relation matrix, $D$ is formed based on pairwise comparisons performed by " $k$ th investor" using a scale of $0-4$ : "0 (No influence)". 1 (Very low influence)". 2 (Low influence)". 3 (High influence)". 4 (Very high influence)". $D$ is $n \times n$ matrix that represents the direct influence of indicator " $i$ " on indicator " $j$ ". In total. $m$ " initial relation matrices are formulated.

Step 2: Grey matrices are formulated by using grey linguistic scale as depicted in Table 2 (Bhatia and Srivastava, 2018).

$\otimes K_{i j}^{y}=\left(\underset{-}{\otimes K_{i j}^{y}}, \bar{\otimes} K_{i j}^{y}\right)$

where $1 \leq y \leq m ; 1 \leq i \leq n ; 1 \leq j \leq n$
Fig. 1 Proposed framework of the study

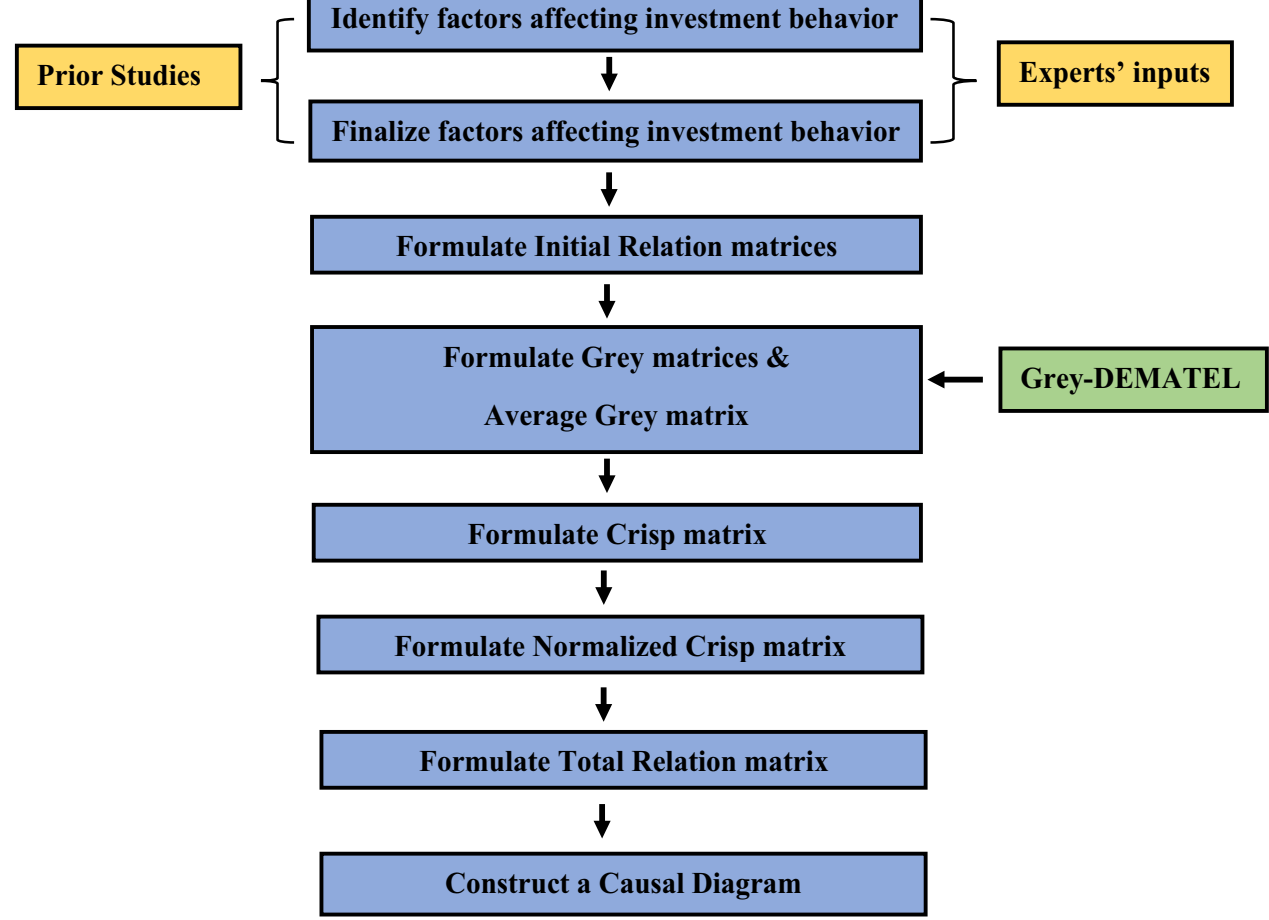




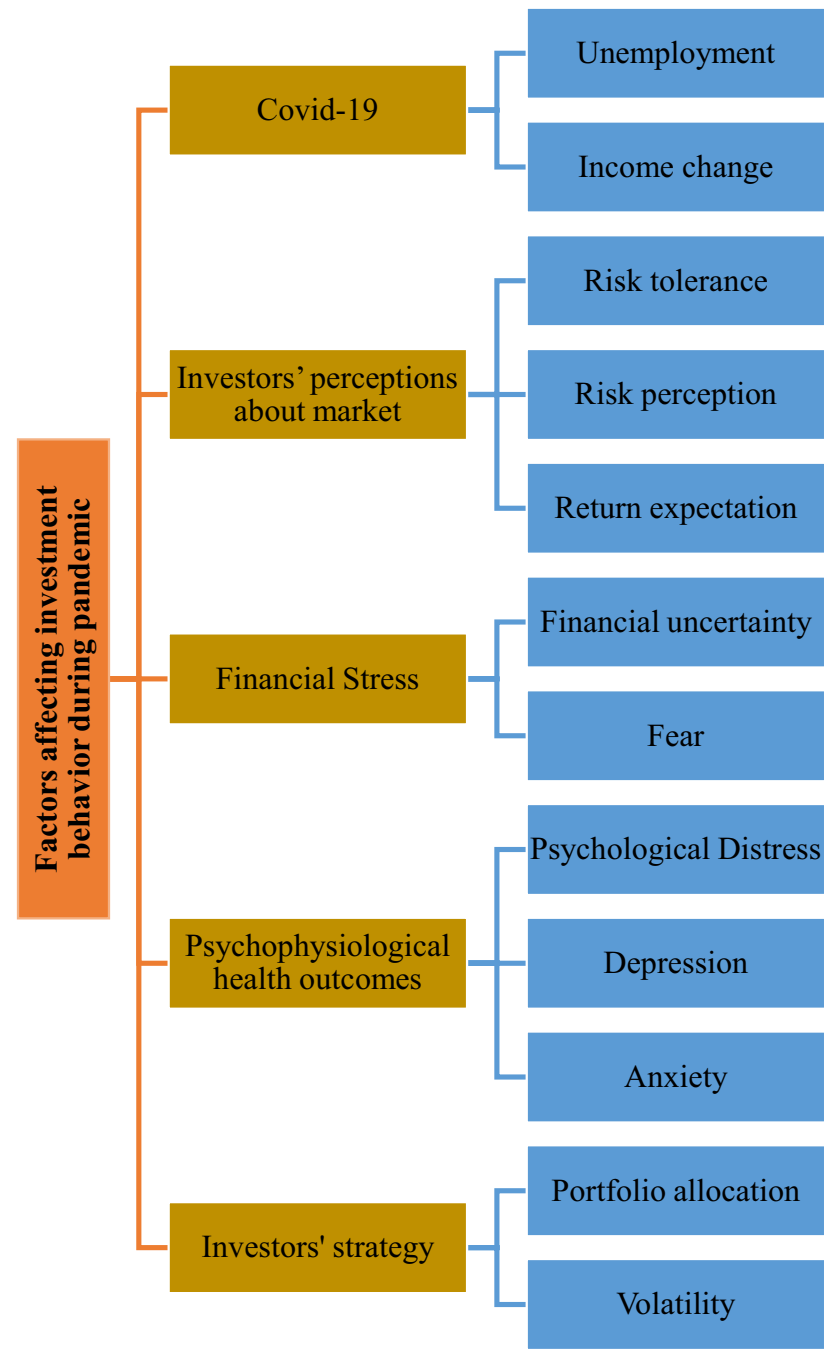

Fig. 2 COVID-19 dimensions and factors affecting investment behavior

Table 2 Grey linguistic scale

\begin{tabular}{ll}
\hline Linguistic assessment & $\begin{array}{l}\text { Correspond- } \\
\text { ing grey } \\
\text { numbers }\end{array}$ \\
\hline No influence & {$[0.00,0.00]$} \\
Very low influence & {$[0.00,0.25]$} \\
Low influence & {$[0.25,0.50]$} \\
High influence & {$[0.50,0.75]$} \\
Very high influence & {$[0.75,1.00]$} \\
\hline
\end{tabular}

Step 3: Average grey matrix is formulated by using Eq. (2)

$\otimes \tilde{K}_{i j}=\left(\frac{\left.\begin{array}{c}\sum_{y} \otimes K^{y} \\ -\end{array}\right]}{m}, \frac{\sum_{y} \bar{\otimes} K_{i j}^{y}}{m}\right)$

where $y=1-m$.

Step 4: Average grey matrix is modified into crisp matrix using modified CFCS method that involves three steps as follows.

(i) Normalized grey values are computed using Eqs. (3)(5)

$\underset{-i j}{\otimes}=\left(\begin{array}{cc}\otimes \tilde{K} & -{ }_{j}^{\min } \otimes \tilde{K} \\ -i j & -i j\end{array}\right) / \Delta_{\min }^{\max }$

where $\otimes \dot{K}$ indicates the normalized lower grey value

$\bar{\otimes} \dot{K}_{i j}=\left(\bar{\otimes} \tilde{K}_{i j}{ }_{j}{ }_{j}^{\min } \bar{\otimes} \tilde{K}_{i j}\right) / \Delta_{\min }^{\max }$

where $\bar{\otimes} \dot{K}_{i j}$ indicates the normalized upper grey value, and

$\Delta_{\min }^{\max }={ }_{j}^{\max } \bar{\otimes} \tilde{K}_{i j}-{ }_{j}{ }_{-i j}^{\min } \otimes \tilde{K}$

(ii) Total normalized crisp value is computed using Eq. (6)

$$
x_{i j}=\left(\frac{\left.\left(\begin{array}{c}
\otimes K_{i j}\left(1-\otimes \dot{K}_{-i j}\right. \\
-{ }_{i j}
\end{array}\right)\right)+\left(\bar{\otimes} \dot{K}_{i j} \times \bar{\otimes} \dot{K}_{i j}\right)}{\left(1-\dot{K}_{i j}+\bar{\otimes} \dot{K}_{i j}\right)}\right)
$$

(iii) Final crisp values are computed using Eqs. (7) and (8)

$$
x_{i j}^{*}=\left(\underset{-i j}{\min \otimes \tilde{K}}+\left(x_{i j} \times \Delta_{\min }^{\max }\right)\right)
$$

and,

$$
X=\left[x_{i j}^{*}\right]
$$

Step 5: Normalized crisp matrix, $Q$ is computed using Eqs. (9) and (10)

$Q=X \times \lambda$ 


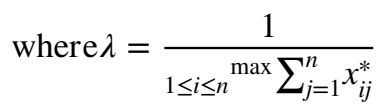

Step 6: Total relation matrix, $P$ is computed using Eq. (11).

$P=Q(\mathrm{I}-Q)^{-1}$

where " $I$ is the identity matrix".

Step 7: The sum of rows in matrix $P$, i.e., $R$, is calculated to show the influence of indicator ' $i$ ' on other indicators. The sum of columns in matrix $P$, i.e., $C$, is calculated to show the impact of other indicators on indicator ' $j$ '. To construct a causal diagram, $\mathrm{R}+\mathrm{C}$ and $\mathrm{R}-\mathrm{C}$ values are represented on horizontal axis and vertical axis, respectively. A threshold value is calculated by taking average of total relation matrix. Only values above this threshold are considered in the casual diagram (Tzeng et al., 2007).

\section{Analysis of results}

This section depicts the empirical outcomes of the study. Table 3 displays the crisp matrix of the interaction of Covid-19 with the main factors (in panel 1) and sub-factors affecting investment behavior (in panel 2) based on Eq. (1).
Likewise, based on Eqs. (2, 3), normalized and total relation matrices are shown in Tables 4 and 5, respectively.

The $\mathrm{R}+\mathrm{C}$ values show the prominence of factors. Table 5 indicates that financial stress (FS) is the most prominent factor affecting investment behavior during the pandemic. Investors believe that people have fixed financial commitments. Due to employment uncertainty due to Covid-19 (CV1) and income change (CV2), investment behavior is being affected by financial stress (FS). The findings confirm with the previous studies (Ji et al., 2020), stating that the health crisis has led to financial turmoil and economic anxiety, which in turn, affects investment behavior (Sahi, 2012; Mazur et al., 2020). Investors assert that financial uncertainty (FS1) leads to depression (PH2), anxiety (PH3), and subsequently to poorer mental health $(\mathrm{PH})$. Findings are in line with Jenkins et al. (2008) and Fitch et al. (2011). They also believe that fear and financial uncertainty lead to volatility in the equity markets. The results are in line with Haroon and Rizvi (2020).

Table 5 reveals that depression (PH2) and anxiety (PH3) caused by Covid-19 (CV) are given the highest weightage among sub-factors. Investors assert that economic hardship acts as a stimulant for anxiety and depression. Our findings are in line with Mirowsky and Ross (2001). The R - C values show the cause-and-effect relationships among factors. COVID-19 (CV) has the highest positive $\mathrm{R}-\mathrm{C}$ value. The value indicates that Covid-19 (CV) is the primary causal

Table 3 Crisp matrix

\begin{tabular}{|c|c|c|c|c|c|c|c|c|c|c|c|c|}
\hline \multicolumn{2}{|l|}{ Main factors } & \multicolumn{2}{|c|}{$\mathrm{CV}$} & & \multicolumn{2}{|l|}{ FS } & $\mathrm{PH}$ & \multicolumn{4}{|c|}{ IP } & IS \\
\hline \multicolumn{13}{|c|}{ Panel 1. Interaction of COVID-19 with main factors affecting investment behavior } \\
\hline \multicolumn{2}{|l|}{$\mathrm{CV}$} & \multicolumn{2}{|c|}{0.000} & \multicolumn{3}{|c|}{0.873} & \multicolumn{2}{|c|}{0.766} & \multicolumn{2}{|c|}{0.731} & & 0.784 \\
\hline FS & & \multicolumn{2}{|c|}{0.340} & \multicolumn{3}{|c|}{0.000} & \multicolumn{2}{|c|}{0.804} & \multicolumn{2}{|c|}{0.733} & & 0.858 \\
\hline $\mathrm{PH}$ & & \multicolumn{2}{|c|}{0.435} & \multicolumn{3}{|c|}{0.634} & \multicolumn{2}{|c|}{0.000} & \multicolumn{2}{|c|}{0.724} & & 0.796 \\
\hline IP & & \multicolumn{2}{|c|}{0.319} & \multicolumn{3}{|c|}{0.355} & \multicolumn{2}{|c|}{0.141} & \multicolumn{2}{|c|}{0.000} & & 0.889 \\
\hline IS & & \multicolumn{2}{|c|}{0.306} & \multicolumn{3}{|c|}{0.498} & \multicolumn{2}{|c|}{0.306} & \multicolumn{2}{|c|}{0.498} & & 0.000 \\
\hline Sub-factors & CV1 & $\mathrm{CV} 2$ & FS1 & FS2 & PH1 & PH2 & PH3 & IP1 & IP2 & IP3 & IS1 & IS2 \\
\hline \multicolumn{13}{|c|}{ Panel 2. Interaction of COVID-19 with sub-factors affecting investment behavior } \\
\hline CV1 & 0.000 & 0.786 & 0.161 & 0.232 & 0.840 & 0.786 & 0.858 & 0.733 & 0.250 & 0.161 & 0.840 & 0.232 \\
\hline CV2 & 0.468 & 0.000 & 0.755 & 0.235 & 0.791 & 0.773 & 0.827 & 0.755 & 0.289 & 0.235 & 0.702 & 0.181 \\
\hline FS1 & 0.395 & 0.198 & 0.000 & 0.753 & 0.771 & 0.699 & 0.735 & 0.843 & 0.198 & 0.252 & 0.789 & 0.789 \\
\hline $\mathrm{FS} 2$ & 0.254 & 0.218 & 0.380 & 0.000 & 0.758 & 0.704 & 0.812 & 0.254 & 0.722 & 0.218 & 0.272 & 0.812 \\
\hline PH1 & 0.252 & 0.269 & 0.234 & 0.681 & 0.000 & 0.753 & 0.843 & 0.252 & 0.789 & 0.269 & 0.216 & 0.234 \\
\hline $\mathrm{PH} 2$ & 0.319 & 0.337 & 0.302 & 0.640 & 0.729 & 0.000 & 0.889 & 0.782 & 0.746 & 0.230 & 0.213 & 0.248 \\
\hline PH3 & 0.327 & 0.291 & 0.291 & 0.796 & 0.688 & 0.237 & 0.000 & 0.291 & 0.724 & 0.273 & 0.201 & 0.291 \\
\hline IP1 & 0.272 & 0.362 & 0.452 & 0.380 & 0.272 & 0.308 & 0.290 & 0.000 & 0.218 & 0.812 & 0.812 & 0.416 \\
\hline IP2 & 0.254 & 0.326 & 0.434 & 0.362 & 0.254 & 0.308 & 0.344 & 0.704 & 0.000 & 0.812 & 0.776 & 0.200 \\
\hline IP3 & 0.321 & 0.338 & 0.338 & 0.338 & 0.231 & 0.356 & 0.267 & 0.321 & 0.428 & 0.000 & 0.873 & 0.820 \\
\hline IS 1 & 0.237 & 0.381 & 0.363 & 0.273 & 0.201 & 0.187 & 0.255 & 0.417 & 0.381 & 0.381 & 0.000 & 0.796 \\
\hline IS2 & 0.299 & 0.356 & 0.470 & 0.394 & 0.375 & 0.299 & 0.318 & 0.470 & 0.489 & 0.546 & 0.451 & 0.000 \\
\hline
\end{tabular}


Table 4 Normalized crisp matrix

\begin{tabular}{|c|c|c|c|c|c|c|c|c|c|c|c|c|}
\hline \multicolumn{2}{|l|}{ Main factors } & \multicolumn{2}{|c|}{$\mathrm{CV}$} & & \multicolumn{2}{|l|}{ FS } & $\mathrm{PH}$ & \multicolumn{4}{|c|}{ IP } & IS \\
\hline \multicolumn{13}{|c|}{ Panel 1. Interaction of COVID-19 with main factors affecting investment behavior } \\
\hline \multicolumn{2}{|l|}{$\mathrm{CV}$} & \multicolumn{2}{|c|}{0.000} & \multicolumn{3}{|c|}{0.263} & \multicolumn{2}{|c|}{0.230} & \multicolumn{2}{|c|}{0.220} & & 0.236 \\
\hline FS & & \multicolumn{2}{|c|}{0.102} & \multicolumn{3}{|c|}{0.000} & \multicolumn{2}{|c|}{0.242} & \multicolumn{2}{|c|}{0.220} & & 0.258 \\
\hline $\mathrm{PH}$ & & \multicolumn{2}{|c|}{0.131} & \multicolumn{3}{|c|}{0.191} & \multicolumn{2}{|c|}{0.000} & \multicolumn{2}{|c|}{0.218} & & 0.239 \\
\hline IP & & \multicolumn{2}{|c|}{0.096} & \multicolumn{3}{|c|}{0.107} & \multicolumn{2}{|c|}{0.043} & \multicolumn{2}{|c|}{0.000} & & 0.267 \\
\hline IS & & \multicolumn{2}{|c|}{0.092} & \multicolumn{3}{|c|}{0.150} & \multicolumn{2}{|c|}{0.092} & \multicolumn{2}{|c|}{0.150} & & 0.000 \\
\hline Sub-factors & CV1 & $\mathrm{CV} 2$ & FS1 & FS2 & PH1 & $\mathrm{PH} 2$ & PH3 & IP1 & IP2 & IP3 & IS1 & IS2 \\
\hline \multicolumn{13}{|c|}{ Panel 2. Interaction of COVID-19 with sub-factors affecting investment behavior } \\
\hline CV1 & 0.000 & 0.122 & 0.025 & 0.036 & 0.131 & 0.122 & 0.133 & 0.114 & 0.039 & 0.025 & 0.131 & 0.036 \\
\hline CV2 & 0.073 & 0.000 & 0.117 & 0.036 & 0.123 & 0.120 & 0.129 & 0.117 & 0.045 & 0.036 & 0.109 & 0.028 \\
\hline FS1 & 0.061 & 0.031 & 0.000 & 0.117 & 0.120 & 0.109 & 0.114 & 0.131 & 0.031 & 0.039 & 0.123 & 0.123 \\
\hline FS2 & 0.039 & 0.034 & 0.059 & 0.000 & 0.118 & 0.109 & 0.126 & 0.039 & 0.112 & 0.034 & 0.042 & 0.126 \\
\hline PH1 & 0.039 & 0.042 & 0.036 & 0.106 & 0.000 & 0.117 & 0.131 & 0.039 & 0.123 & 0.042 & 0.034 & 0.036 \\
\hline $\mathrm{PH} 2$ & 0.050 & 0.052 & 0.047 & 0.099 & 0.113 & 0.000 & 0.138 & 0.121 & 0.116 & 0.036 & 0.033 & 0.039 \\
\hline PH3 & 0.051 & 0.045 & 0.045 & 0.124 & 0.107 & 0.037 & 0.000 & 0.045 & 0.112 & 0.042 & 0.031 & 0.045 \\
\hline IP1 & 0.042 & 0.056 & 0.070 & 0.059 & 0.042 & 0.048 & 0.045 & 0.000 & 0.034 & 0.126 & 0.126 & 0.065 \\
\hline IP2 & 0.039 & 0.051 & 0.067 & 0.056 & 0.039 & 0.048 & 0.053 & 0.109 & 0.000 & 0.126 & 0.121 & 0.031 \\
\hline IP3 & 0.050 & 0.053 & 0.053 & 0.053 & 0.036 & 0.055 & 0.041 & 0.050 & 0.066 & 0.000 & 0.136 & 0.127 \\
\hline IS1 & 0.037 & 0.059 & 0.056 & 0.042 & 0.031 & 0.029 & 0.040 & 0.065 & 0.059 & 0.059 & 0.000 & 0.124 \\
\hline IS2 & 0.046 & 0.055 & 0.073 & 0.061 & 0.058 & 0.046 & 0.049 & 0.073 & 0.076 & 0.085 & 0.070 & 0.000 \\
\hline
\end{tabular}

Table 5 Total relation matrix

\begin{tabular}{|c|c|c|c|c|c|c|c|c|c|c|c|c|c|c|}
\hline \multicolumn{2}{|l|}{ Main factors } & \multicolumn{2}{|l|}{$\mathrm{CV}$} & \multicolumn{2}{|l|}{ FS } & \multicolumn{2}{|l|}{$\mathrm{PH}$} & \multicolumn{2}{|l|}{ IP } & \multicolumn{2}{|l|}{ IS } & \multicolumn{2}{|l|}{$\mathrm{R}+\mathrm{C}$} & $\mathrm{R}-\mathrm{C}$ \\
\hline \multicolumn{15}{|c|}{ Panel 1. Interaction of COVID-19 with main factors affecting investment behavior } \\
\hline \multicolumn{2}{|l|}{$\mathrm{CV}$} & \multicolumn{2}{|l|}{0.265} & \multicolumn{2}{|l|}{0.616} & \multicolumn{2}{|l|}{0.537} & \multicolumn{2}{|l|}{0.644} & \multicolumn{2}{|l|}{0.758} & \multicolumn{2}{|l|}{4.195} & 1.445 \\
\hline \multicolumn{2}{|l|}{ FS } & \multicolumn{2}{|l|}{0.319} & \multicolumn{2}{|l|}{0.341} & \multicolumn{2}{|l|}{0.486} & \multicolumn{2}{|l|}{0.574} & \multicolumn{2}{|l|}{0.691} & \multicolumn{2}{|l|}{4.522} & 0.299 \\
\hline \multicolumn{2}{|l|}{$\mathrm{PH}$} & \multicolumn{2}{|l|}{0.331} & \multicolumn{2}{|l|}{0.489} & \multicolumn{2}{|l|}{0.279} & \multicolumn{2}{|l|}{0.557} & \multicolumn{2}{|l|}{0.659} & \multicolumn{2}{|l|}{4.122} & 0.508 \\
\hline \multicolumn{2}{|l|}{ IP } & \multicolumn{2}{|l|}{0.231} & 0.316 & & 0.231 & & 0.249 & & 0.525 & & 3.960 & & -0.856 \\
\hline IS & & 0.229 & & 0.349 & & 0.274 & & 0.383 & & 0.312 & & 4.492 & & -1.397 \\
\hline Sub-factors & CV1 & CV2 & FS1 & $\mathrm{FS} 2$ & PH1 & $\mathrm{PH} 2$ & PH3 & IP1 & IP2 & IP3 & IS1 & IS2 & $\mathrm{R}+\mathrm{C}$ & $\mathrm{R}-\mathrm{C}$ \\
\hline Panel 2. Inte & action of & COVID- & 9 with st & b-factor & affectin & investme & t behav & & & & & & & \\
\hline CV1 & 0.178 & 0.312 & 0.245 & 0.310 & 0.417 & 0.381 & 0.447 & 0.394 & 0.324 & 0.251 & 0.414 & 0.289 & 6.315 & 1.609 \\
\hline CV2 & 0.253 & 0.206 & 0.331 & 0.324 & 0.422 & 0.390 & 0.455 & 0.409 & 0.337 & 0.269 & 0.409 & 0.297 & 6.735 & 1.468 \\
\hline FS1 & 0.248 & 0.244 & 0.234 & 0.404 & 0.428 & 0.388 & 0.452 & 0.427 & 0.341 & 0.284 & 0.430 & 0.396 & 7.163 & 1.385 \\
\hline $\mathrm{FS} 2$ & 0.202 & 0.215 & 0.256 & 0.257 & 0.381 & 0.347 & 0.413 & 0.306 & 0.371 & 0.245 & 0.312 & 0.350 & 7.238 & 0.072 \\
\hline PH1 & 0.185 & 0.204 & 0.216 & 0.328 & 0.250 & 0.330 & 0.390 & 0.279 & 0.355 & 0.230 & 0.278 & 0.249 & 7.215 & -0.627 \\
\hline $\mathrm{PH} 2$ & 0.212 & 0.233 & 0.247 & 0.349 & 0.380 & 0.251 & 0.426 & 0.377 & 0.374 & 0.251 & 0.311 & 0.276 & 7.258 & 0.115 \\
\hline PH3 & 0.185 & 0.196 & 0.212 & 0.325 & 0.328 & 0.249 & 0.253 & 0.266 & 0.327 & 0.218 & 0.263 & 0.245 & 7.332 & -1.202 \\
\hline IP1 & 0.181 & 0.210 & 0.239 & 0.266 & 0.269 & 0.255 & 0.291 & 0.227 & 0.252 & 0.295 & 0.358 & 0.277 & 6.970 & -0.730 \\
\hline IP2 & 0.183 & 0.210 & 0.242 & 0.270 & 0.272 & 0.260 & 0.305 & 0.335 & 0.224 & 0.304 & 0.364 & 0.253 & 6.940 & -0.496 \\
\hline IP3 & 0.187 & 0.208 & 0.224 & 0.260 & 0.263 & 0.260 & 0.288 & 0.278 & 0.282 & 0.182 & 0.364 & 0.328 & 6.123 & 0.126 \\
\hline IS1 & 0.156 & 0.191 & 0.204 & 0.222 & 0.228 & 0.209 & 0.251 & 0.258 & 0.243 & 0.214 & 0.209 & 0.293 & 6.697 & -1.341 \\
\hline IS2 & 0.183 & 0.207 & 0.239 & 0.268 & 0.283 & 0.253 & 0.295 & 0.294 & 0.288 & 0.258 & 0.305 & 0.207 & 6.541 & -0.380 \\
\hline
\end{tabular}


Fig. 3 Casual diagram of COVID-19 and main factors affecting investment behavior

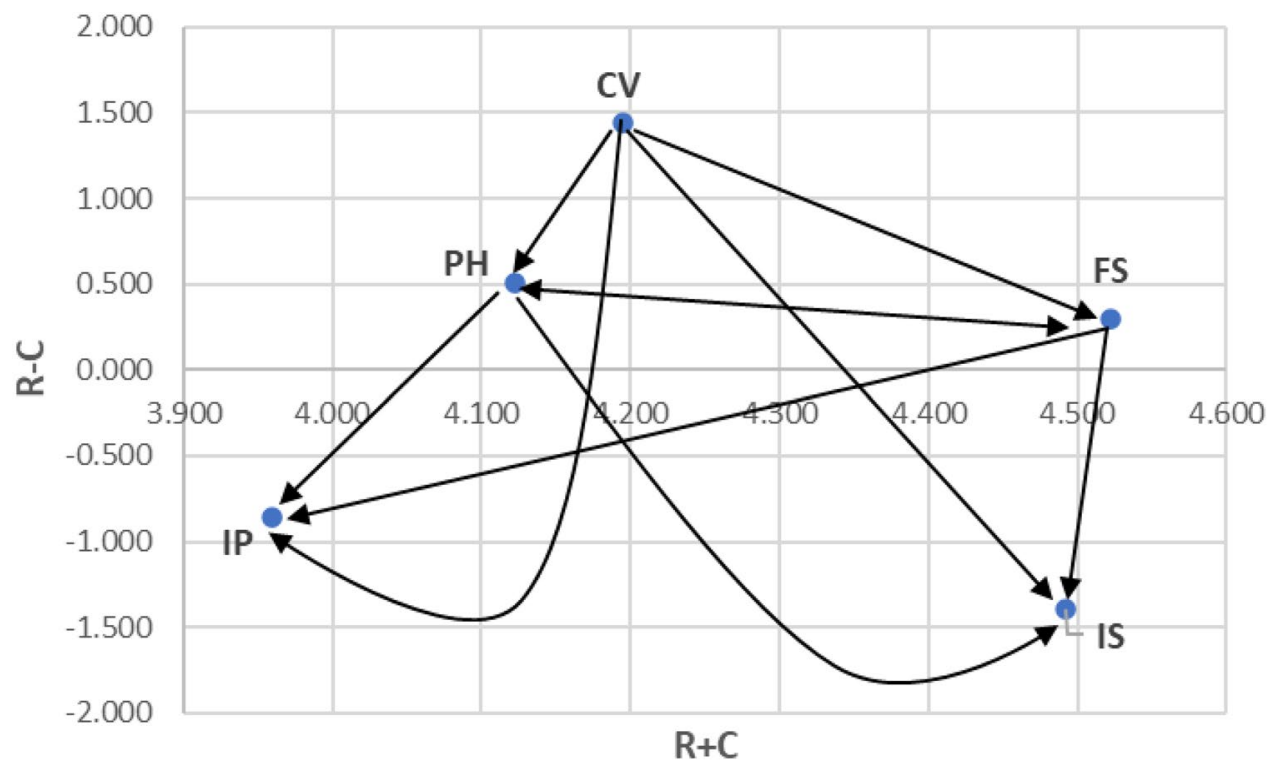

factor. The causal diagram of Covid-19 and the main factors affecting investment behavior based on the threshold value of 0.426 are shown in Fig. 3. The figure depicts that Covid19 (CV) affects all factors which are taken under investment behavior. Investors perceive that Covid-19 (CV) is the leading cause behind financial stress (FS), psychophysiological health outcomes (PH), investors' perception about the market (IP), and investors' strategy (IS). Covid-19 has deteriorated personal financial situation and has created financial threat among people. Studies have also provided evidence in favor of investors' opinion that the Covid-19 has led to fear in the stock markets (Qian and Fan, 2020; Salisu and Akanni, 2020). This fear of investors became evident and resulted in the stock market crashes for many days following the news of Covid-19 and complete lockdown. Stock market collapses lead to anxiety, panic, and fear of unrestrained trading losses (Sperling et al., 2008). Thus, the health crisis has led to financial turmoil.

The results reflect that Covid-19 (CV) has led to many psychophysiological health outcomes (PH) such as psychological distress (PH1), depression (PH2), and anxiety (PH3). These psychophysiological health outcomes are apparent in society in the form of an increase in the number of suicides. The findings are in conformity with Mann et al. (2020) and Rajkumar (2020).

The results also show that Covid-19 (CV) has altered the risk tolerance (IP1) and risk perceptions (IP2) of investors. Academic literature states that as the value of portfolios of the investors declines during the financial crisis, they become fearful and enraged due to uncertainty of their future. They become irrational and reluctant to show tolerance and expectation for the market upturn in future (Mushinada, 2020). Also, investors turn out to be risk averters and consequentially decrease their allocation in equity due to a rise in perceived risk (Baker and Ricciardi, 2014). The total investment amount has decreased along with a fall in the return expectations of investors (Akhtaruzzaman et al., 2020; Ashraf, 2020; Azimli, 2020). Risk- return relationship during the Covid-19 has changed, thus leading to less benefits of diversification (Azimli, 2020). Investors opine that the Covid-19 pandemic (CV) has led to increased uncertainty and volatility (IS2). The findings are similar to Ali et al. (2020) and Mazur et al. (2020) who showed that Covid19 has led to extreme volatility and excessive uncertainty. Rising unemployment, income changes, and negative GDP resulted in a loss of investors' confidence. Long-term expectations coupled with investor sentiments induced exaggerated movement in security prices. The findings confirm with the studies stating that uncertainty and huge economic losses during the pandemic have led to greater unpredictable and volatile stock markets (Demir et al., 2020).

Besides, both financial stress (FS) and psychophysiological health outcomes (PH) influence the investors' perceptions and strategies (IP and IS). Investors assert that investors have responded to the pandemic by changing their strategies and portfolios (IS1). Change in investment strategies is being witnessed worldwide. Investors have started selling risky assets and shifting on to safe-haven investments like gold and silver (Ji et al., 2020; Himanshu et al., 2021). While gold has maintained its reputation as a safe-haven investment, cryptocurrency such as bitcoin has failed to prove its worth during financial crisis (Conlon and McGee, 2020; Corbet et al., 2020). The results also signify the argument put forth by Olsen et al. (1998), stating that decision-makers modify their decisions depending upon the prevailing environmental conditions.

Figure 4 shows the causal diagram of COVID-19 dimensions and sub-factors affecting investment behavior based 
Fig. 4 Casual diagram of COVID-19 and sub-factors affecting investment behavior

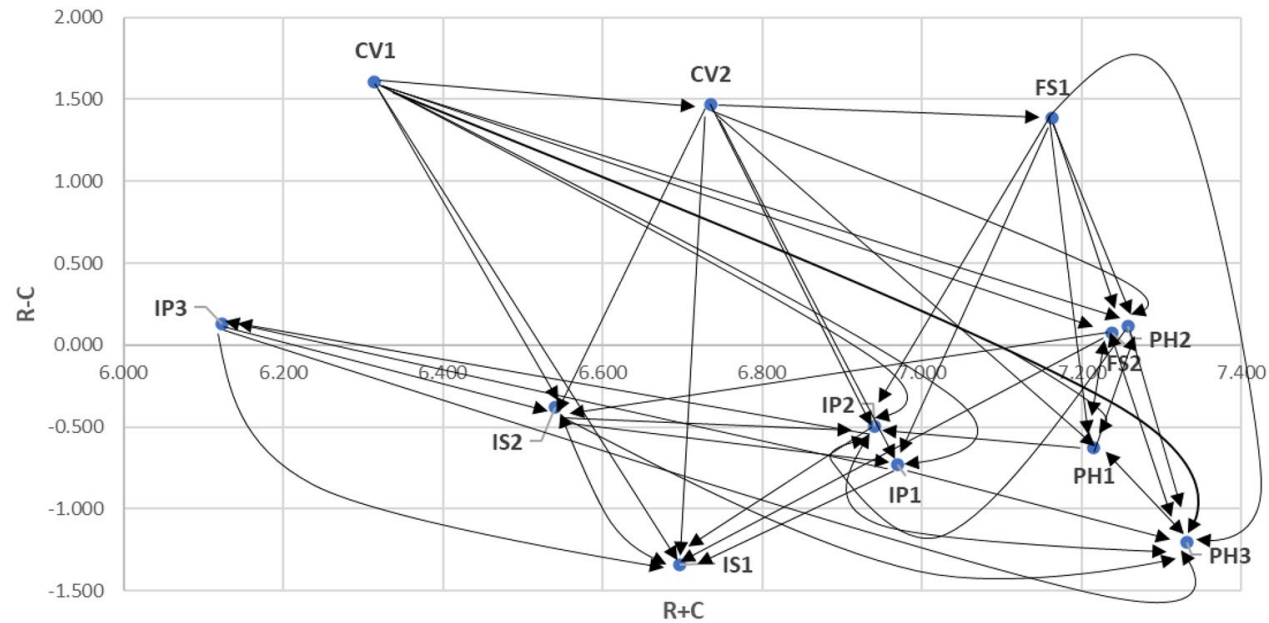

on a threshold value of 0.287 . Specifically, the figure shows the contextual relationships between identified dimensions for COVID-19 (CV) [Unemployment (CV1), Income change (CV2)] and sub-factors affecting investment behavior.

Unemployment (CV1) and income change (CV2) are the primary causal sub-factor influencing other sub-factors such as fear (FS2), psychological distress (PH1), depression (PH2), anxiety (PH3), risk tolerance (IP1), risk perceptions (IP2), portfolio allocation (IS1), and volatility (IS2). Findings are akin to the studies (Kahneman and Deaton, 2010; Roszkowski and Davey, 2010; Tefft, 2011) studies stating that low income and unemployment adversely affect emotional well-being. Investors perceive that investment behavior is being impacted due to unemployment (CV1) and income changes (CV2).

Figure 4 shows that portfolio allocation (IS1) is the most influenced sub-factor. Investors assert that investors communicate the effect of any phenomenon by reallocating their portfolios. Their loss aversion tendency motivates them to alter their portfolios. During the financial turbulence, the investors reapportion their portfolios by investing more in safe-haven investments, which are negatively correlated with other market securities. The results are in line with Conlon and McGee (2020).

\section{Implications of the study}

The study outlines the impact of epidemic and financial crisis on investment behavior. For various stakeholders in society, this study offers useful theoretical and practical implications. This study contributes to the literature related to the impact of the pandemic on investment behavior. This study will work as a reference for understanding investors' perception, psychophysiological health outcomes, and investors' strategy during a pandemic.
For practical implications, the study will be immensely useful to the government and policymakers while devising the policies for combating the effect of financial crisis on investors, financial markets, and the economy at large. They would get an understanding of the causes and potential consequences of the pandemic on investment behavior. The research will also be useful to the financial advisors to reduce the impact of emotions on the financial decisions of investors.

\section{Conclusion and future research}

Covid-19 has affected the economies throughout the world. Plunging demand and staggering economies have created fear and panic among investors leading to increased volatility and stock market crashes. The study intends to examine the cause-and-effect relationship between Covid-19 and the factors affecting investment behavior. Experts assisted in finalization of factors. The cause-and-effect relationships among them are examined using pairwise comparisons made by the investors. The study reveals that Covid-19 affects all these factors.

Due to decreasing income and unemployment, the investors have suffered from adverse psychophysiological health outcomes which have made them more risk-averse. They have changed their investment strategies and portfolios by moving from highly risky investments to safe-haven investments. This study shows that the risk is affected by feelings and during uncertainty, decisions are guided by emotions. This study adds to the literature signaling toward the instability of risk preferences.

The study not only extends the literature related to the effect of pandemic on investment behavior, but also provides the cause-and-effect relationship among the factors affecting investment behavior during the pandemic. This paper shows that what seems just an aftermath of 
a pandemic is in real sense a result of lot of psychological and physiological issues. Investors try to herd during a financial crisis in order to minimize the negative outcomes. The results of the present study can also be attributed to the tendency of investors to minimize regret and cognitive dissonance. Various direct and indirect research hypothesis can be derived using the cause-and-effect relationships established by this paper.

Government policy measures have also fallen short of expectations. Although the effects of the recession, driven due to the pandemic, can be seen over the economies in the long run, the negative impact is expected to diminish after vaccination. Future research can be aimed at analyzing the long-term effects of a Covid-19 on various financial and economic systems of emerging and developed economies. Researchers can also explore other factors affecting investment behavior during the pandemic. This paper can be used as a foundation to generalize the results by taking investors' opinions in other developed and developing economies.

Authors' contribution Ritika: Theoretical Background, Introduction of Topic, Review of Literature, and Discussion of Results. Himanshu: Research Methodology, Data Collection, and Data Analysis. Prof. Nawal Kishor: Conceptualization and Discussion of Results.

\section{Declarations}

Conflict of interest All authors declare that they have no conflict of interest.

\section{References}

Akhtaruzzaman, M., S. Boubaker, and A. Sensoy. 2020. Financial contagion during Covid-19 crisis. Finance Research Letters 38: $1-20$.

Al-Awadhi, A., K. Alsaifi, A. Al-Awadhi, and S. Alhammadi. 2020. Death and contagious infectious diseases: Impact of the COVID19 virus on stock market returns. Journal of Behavioral and Experimental Finance 27: 1-5.

Ali, M., N. Alam, and S.A.R. Rizvi. 2020. Coronavirus (Covid-19)An epidemic or pandemic for financial markets. Journal of Behavioral and Experimental Finance 27: 1-6.

Alon, T., Doepke, M., Olmstead-Rumsey, J. and Tertilt, M. 2020. This time it's different: the role of women's employment in a pandemic recession. Working paper, National Bureau of Economic Research, Cambridge, MA.

Arndt, C., and J.D. Lewis. 2001. The HIV/AIDS pandemic in South Africa: Sectoral impacts and unemployment. Journal of International Development 13 (4): 427-449.

Ashraf, B.N. 2020. Economic impact of government interventions during the Covid19 pandemic: International evidence from financial markets. Journal of Behavioral and Experimental Finance 27: $1-9$.

Azimli, A. 2020. The impact of COVID-19 on the degree of dependence and structure of risk-return relationship: A quantile regression approach. Finance Research Letters 36: 1-5.
Badshah, I., S. Bekiros, B. Lucey, and G. Uddin. 2018. A symmetric linkages among the fear index and emerging market volatility indices. Emerging Markets Review 37: 17-31.

Baker, H.K., and V. Ricciardi. 2014. Investor Behavior: The Psychology of Financial Planning and Investing. New York: Wiley.

Bhatia, M.S., and R.K. Srivastava. 2018. Analysis of external barriers to remanufacturing using grey-DEMATEL approach: An Indian perspective. Resources, Conservation and Recycling 136: 79-87.

Brown, S., K. Taylor, and S.W. Price. 2005. Debt and distress: Evaluating the psychological cost of credit. Journal of Economic Psychology 26 (5): 642-663.

Burns, W., E. Peters, and P. Slovic. 2012. Risk perception and the economic crisis: A longitudinal study of the trajectory of perceived risk. Risk Analysis 32 (4): 659-677.

Combs, A., M. Samy, and A. Myachina. 2013. Cultural impact on the harmonisation of Russian accounting standards with the International Financial Reporting Standards: A practitioner's perspective. Journal of Accounting and Organizational Change 9 (1): $26-49$.

Conlon, T., and R. McGee. 2020. Safe haven or risky hazard? Bitcoin during the COVID-19 bear market. Finance Research Letters 35: $1-5$.

Corbet, S., C. Larkin, and B. Lucey. 2020. The contagion effects of the Covid-19 pandemic: Evidence from gold and cryptocurrencies. Finance Research Letters 35: 1-7.

Corter, J. 2011. Does investment risk tolerance predict emotional and behavioural reactions to market turmoil. International Journal of Behavioural Accounting and Finance 2 (3-4): 225-237.

Cox, N., Ganong, P., Noel, P., Vavra, J., Wong, A., Farrell, D. and Greig, F. 2020. Initial impacts of the pandemic on consumer behavior: evidence from linked income, spending, and savings data. Working paper, Becker Friedman Institute for Economics, University of Chicago, Illinois.

Davis, S., and J. Madura. 2012. How the shift to quality distinguished winners from losers during the financial crisis. Journal of Behavioral Finance 13 (2): 81-92.

Demir, E., M.H. Bilgin, G. Karabulut, and A.C. Doker. 2020. The relationship between cryptocurrencies and Covid-19 pandemic. Eurasian Economic Review 10: 349-360.

Diener, E., W. Ng, J. Harter, and R. Arora. 2010. Wealth and happiness across the world: Material prosperity predicts life evaluation, whereas psychosocial prosperity predicts positive feeling. Journal of Personality and Social Psychology 99 (1): 52-61.

Dzielinski, M. 2012. Measuring economic uncertainty and its impact on the stock market. Finance Research Letters 9 (3): 167-175.

Economou, F., Y. Panagopoulos, and E. Tsouma. 2018. Uncovering asymmetries in the relationship between fear and the stock market using a hidden co-integration approach. Research in International Business and Finance 44: 459-470.

Engardio, P. 2006. Chindia: How China and India are revolutionizing Global Business. New York: McGraw-Hill Professional.

Fitch, C., S. Hamilton, P. Bassett, and R. Davey. 2011. The relationship between personal debt and mental health: A systematic review. Mental Health Review Journal 16 (4): 153-166.

Fjellstrom, D., T. Fang, and D. Chimenson. 2019. Explaining reshoring in the context of Asian competitiveness: Evidence from a Swedish firm. Journal of Asia Business Studies 13 (2): 277-293.

Gabus, A., and E. Fontela. 1972. World problems, an invitation to further thought within the framework of DEMATEL. Geneva: Battelle Geneva Research Center.

Gerrans, P., R. Faff, and N. Hartnett. 2013. Individual financial risk tolerance and the global financial crisis. Accounting and Finance 55 (1): 165-185.

Ghosh, J. 2020. A critique of the Indian government's response to the Covid-19 pandemic. Journal of Industrial and Business Economics 47 (3): 519-530. 
Glaser, M., and M. Weber. 2005. September 11 and stock return expectations of individual investors. Review of Finance 9 (2): 243-279.

Grable, J.E., W. Heo, and A. Rabbani. 2021. Characteristics of random responders in a financial risk-tolerance questionnaire. Journal of Financial Services Marketing 26 (1): 1-9.

Gradinaru, A. 2014. The contribution of behavioral economics in explaining the decisional process. Procedia Economics and Finance 16: 417-426.

Guiso, L., P. Sapienza, and L. Zingales. 2018. Time varying risk aversion. Journal of Financial Economics 128 (3): 403-421.

Gupta, H., and M.K. Barua. 2017. Supplier selection among SMEs on the basis of their green innovation ability using BWM and fuzzy TOPSIS. Journal of Cleaner Production 152: 242-258.

Gupta, H., and M.K. Barua. 2018. A grey DEMATEL-based approach for modeling enablers of green innovation in manufacturing organizations. Environmental Science and Pollution Research 25 (10): 9556-9578.

Haapio, H., Mero, J., Karjaluoto, H. and Shaikh, A.A. 2021. Implications of the COVID-19 pandemic on market orientation in retail banking. Journal of Financial Services Marketing, 1-10.

Han, L., W. Tang, Y. Liu, J. Wang, and C. Fu. 2013. Evaluation of measurement uncertainty based on grey system theory for small samples from an unknown distribution. Science China Technological Sciences 56 (6): 1517-1524.

Haroon, O. and Rizvi, S. 2020. COVID-19: Media coverage and financial markets behavior-A sectoral inquiry. Journal of Behavioral and Experimental Finance 27: 100343.

Harris, M., and A. Raviv. 1993. Differences of opinion make a horse race. The Review of Financial Studies 6 (3): 473-506.

Hasan, F., and M. Kashif. 2020. Psychological safety, meaningfulness and empowerment as predictors of employee well-being: A mediating role of promotive voice. Asia-Pacific Journal of Business Administration 13 (1): 40-59.

Hens, T., and K. Bachmann. 2008. Behavioural Finance for Private Banking. New York: Wiley.

Herberger, T.A., and F. Reinle. 2020. A framework for screening and portfolio selection in corporate venture capital. Studies in Economics and Finance 37 (3): 475-495.

Himanshu, Ritika, N. Mushir, and R. Suryavanshi. 2021. Impact of Covid-19 on portfolio allocation decisions of individual investors. Journal of Public Affairs. https://doi.org/10.1002/pa.2649.

Himanshu, S., and A. Kumar. 2020. Prioritizing and establishing cause and effect relationships among financial reporting quality metrics. Vision-The Journal of Business Perspective 24 (3): 330-344.

Hoffmann, A., T. Post, and J. Pennings. 2013. Individual investor perceptions and behavior during the financial crisis. Journal of Banking and Finance 37 (1): 60-74.

Jalan, B. 2011. India's economy in the 21st century: A new beginning or a false dawn? India International Centre Quarterly 38 (3/4): 230-247.

Jenkins, R., D. Bhugra, P. Bebbington, T. Brugha, M. Farrell, and J. Coid. 2008. Debt, income and mental disorder in the general population. Psychological Medicine 38 (10): 1485-1493.

Ji, Q., D. Zhang, and Y. Zhao. 2020. Searching for safe-haven assets during the COVID-19 pandemic. International Review of Financial Analysis 71: 1-10.

Julong, D. 1989. Introduction to grey system theory. The Journal of Grey System 1 (1): 1-24.

Kahneman, D., and A. Deaton. 2010. High income improves evaluation of life but not emotional well-being. Proceedings of the National Academy of Sciences of the United States of America 107 (38): 16489-16493.

Khawaja, M.J., and Z.N. Alharbi. 2021. Factors influencing investor behavior: An empirical study of Saudi Stock Market. International Journal of Social Economics 48 (4): 587-601.
Kubzansky, L., I. Kawachi, A. Spiro, S. Weiss, P. Vokonas, and D. Sparrow. 1997. Is worrying bad for your heart? Circulation 95 (4): $818-824$

Kumar, A. and Anbanandam, R. 2020a. Analyzing interrelationships and prioritising the factors influencing sustainable intermodal freight transport system: A grey-DANP approach. Journal of Cleaner Production, 252:119769.

Kumar, A., and R. Anbanandam. 2020b. Evaluating the interrelationships among inhibitors to intermodal railroad freight transport in emerging economies: A multi-stakeholder perspective. Transportation Research Part a: Policy and Practice 132: 559-581.

Kumar, A., and G. Dixit. 2018. Evaluating critical barriers to implementation of WEEE management using DEMATEL approach. Resources, Conservation and Recycling 131: 101-121.

Leduc, S., and Z. Liu. 2020. The uncertainty channel of the coronavirus. FRBSF Economic Letter 7: 1-5.

Lee, W., C. Jiang, and D. Indro. 2002. Stock market volatility, excess returns, and the role of investor sentiment. Journal of Banking and Finance 26 (12): 2277-2299.

Lerner, J., and D. Keltner. 2000. Beyond valence: Toward a model of emotion-specific influences on judgement and choice. Cognition and Emotion 14 (4): 473-493.

Lin, R.J. 2013. Using fuzzy DEMATEL to evaluate the green supply chain management practices. Journal of Cleaner Production 40: 32-39.

Liu, J., and J.Z. Qiao. 2014. A grey rough set model for evaluation and selection of software cost estimation methods. Grey Systems: Theory and Application 4 (1): 3-12.

Malmendier, U., and S. Nagel. 2011. Depression babies: Do macroeconomic experiences affect risk taking? The Quarterly Journal of Economics 126 (1): 373-416.

Mann, F.D., R.F. Krueger, and K.D. Vohs. 2020. Personal economic anxiety in response to Covid-19. Personality and Individual Differences 167: 1-7.

Mathew, M., R.K. Chakrabortty, and M.J. Ryan. 2020. A novel approach integrating AHP and TOPSIS under spherical fuzzy sets for advanced manufacturing system selection. Engineering Applications of Artificial Intelligence 96: 103988.

Mathew, M., and S. Sahu. 2018. Comparison of new multi-criteria decision-making methods for material handling equipment selection. Management Science Letters 8 (3): 139-150.

Mazur, M., M. Dang, and M. Vega. 2020. COVID-19 and the March 2020 stock market crash. Evidence from S\&P1500. Finance Research Letters 38: 1-8.

Memon, M.S., Y.H. Lee, and S.I. Mari. 2015. Group multi-criteria supplier selection using combined grey systems theory and uncertainty theory. Expert Systems with Applications 42 (21): 7951-7959.

Ministry of Statistics and Programme Implementation 2020. Estimates of gross domestic product for the first quarter April-June of 2020-21. Available at: http://mospi.nic.in/sites/default/files/ press_release/PRESS_NOTE-Q1_2020-21.pdf. Accessed 31 August, 2020.

Mirowsky, J., and C.E. Ross. 2001. Age and the effect of economic hardship on depression. Journal of Health and Social Behavior 42 (2): 132-150.

Mishra, A.K., B.N. Rath, and A.K. Dash. 2020. Does the Indian financial market nosedive because of the Covid-19 outbreak, in comparison to after demonetisation and the GST? Emerging Markets Finance and Trade 56 (10): 2162-2180.

Morin R. 2010. One recession, two Americas. Social and demographic trends report, Pew Research Center, Washington, DC, 24 September. Available at: http://www.pewsocialtrends.org/files/2010/ 10/766-one-recession-two-americas.pdf. Accessed 30 August, 2020. 
Mudgill, A. 2021. Covid 2.0: How it may pan out for Indian economy, markets?. The Economic Times, 12 April. Available at: https://economictimes.indiatimes.com/markets/stocks/news/ covid-2-0-how-it-may-pan-out-for-indian-economy-marke ts/articleshow/82028121.cms?from $=$ mdr. Accessed 14 April 2021.

Mushinada, V.N.C. 2020. How do investors behave in the context of a market crash? Evidence from India. International Journal of Emerging Markets 15 (6): 1201-1217.

Narayan, P. 2019. Can stale oil price news predict stock returns? Energy Economics 83: 430-444.

Nguyen, P.H., J.F. Tsai, I.E. Kayral, and M.H. Lin. 2021. Unemployment rates forecasting with grey-based models in the postCOVID-19 period: A case study from Vietnam. Sustainability 13 (14): 7879.

Nguyen, P.H., J.F. Tsai, H.P. Nguyen, V.T. Nguyen, and T.K. Dao. 2020. Assessing the unemployment problem using a grey MCDM model under Covid-19 impacts: A case analysis from Vietnam. The Journal of Asian Finance, Economics, and Business 7 (12): 53-62.

Olsen, J.R., J.H. Lambert, and Y.Y. Haimes. 1998. Risk of extreme events under nonstationary conditions. Risk Analysis 18 (4): 497-510.

Olsen, R. 2000. The instinctive mind on wall street: Evolution and investment decision making. The Journal of Investing 9 (4): $47-54$.

Oquaye, M., G.M.Y. Owusu, and G.A. Bokpin. 2020. The antecedents and consequence of financial well-being: A survey of parliamentarians in Ghana. Review of Behavioral Finance. https:// doi.org/10.1108/RBF-12-2019-0169.

Patil, S.K., and R. Kant. 2014. A hybrid approach based on fuzzy DEMATEL and FMCDM to predict success of knowledge management adoption in supply chain. Applied Soft Computing 18: 126-135.

Phan, D., and P. Narayan. 2020. Country responses and the reaction of the stock market to Covid-19-A preliminary exposition. Emerging Markets Finance and Trade 56 (10): 2138-2150.

Qian, Y., and W. Fan. 2020. Who loses income during the COVID-19 outbreak? Evidence from China. Research in Social Stratification and Mobility 68: 1-5.

Rajkumar, R.P. 2020. Covid-19 and mental health: A review of the existing literature. Asian Journal of Psychiatry 52: 1-5.

Rathi, N., and K. Lee. 2017. Role of basic psychological need satisfaction in retaining talent: An investigation in the Indian context. Asia-Pacific Journal of Business Administration 9 (1): $2-15$.

Ritika, and N. Kishor. 2020. Development and validation of behavioral biases scale: A SEM approach. Review of Behavioral Finance. https://doi.org/10.1108/RBF-05-2020-0087.

Roszkowski, M.J., and G. Davey. 2010. Risk perception and risk tolerance changes attributable to the 2008 economic crisis: A subtle but critical difference. Journal of Financial Service Professionals 64 (4): 42-53.

Sahi, S.K. 2012. Neurofinance and investment behaviour. Studies in Economics and Finance 29 (4): 246-267.

Salisu, A., and L. Akanni. 2020. Constructing a global fear index for the Covid-19 pandemic. Emerging Markets Finance and Trade 56 (10): 2310-2331.

Seker, S., F. Recal, and H. Basligil. 2017. A combined DEMATEL and grey system theory approach for analyzing occupational risks: A case study in Turkish shipbuilding industry. Human and Ecological Risk Assessment: An International Journal 23 (6): 1340-1372.

Sharma, Y. S. 2020. Unemployment rate shoots up to $8.4 \%$ in August as rural jobs disappear. The Economic Times, 4 September. Available at: https://economictimes.indiatimes.com/news/ economy/indicators/unemployment-rate-shoots-up-to-8-4-inaugust-as-rural-jobs-disappear/articleshow/77908860.cms. Accessed 7 September, 2020.

Siegrist, M., T. Earle, and H. Gutscher. 2003. Test of a trust and confidence model in the applied context of electromagnetic field emf risks. Risk Analysis 23 (4): 705-716.

Siegrist, M., H. Gutscher, and T. Earle. 2005. Perception of risk: The influence of general trust, and general confidence. Journal of Risk Research 8 (2): 145-156.

Singh, S.K., and S.S. Gaur. 2020. Managing organization and business in Asia. Journal of Asia Business Studies 14 (2): 141-142.

Sperling, W., S. Bleich, and U. Reulbach. 2008. Black Monday on stock markets throughout the world-A new phenomenon of collective panic disorder? A psychiatric approach. Medical Hypotheses 71 (6): 972-974.

Stevenson, B. and Wolfers, J. 2008. Economic growth and subjective well-being: Reassessing the Easterlin paradox. Working paper, National Bureau of Economic Research, Cambridge, MA.

Su, C.M., D.J. Horng, M.L. Tseng, A.S. Chiu, K.J. Wu, and H.P. Chen. 2016. Improving sustainable supply chain management using a novel hierarchical grey-DEMATEL approach. Journal of Cleaner Production 134: 469-481.

Taqi, H.M., H.N. Ahmed, S. Paul, M. Garshasbi, S.M. Ali, G. Kabir, and S.K. Paul. 2020. Strategies to manage the impacts of the COVID-19 pandemic in the supply chain: Implications for improving economic and social sustainability. Sustainability 12 (22): $1-25$.

Tefft, N. 2011. Insights on unemployment, unemployment insurance and mental health. Journal of Health Economics 30 (2): $258-264$.

India Today 2020. Income of $63 \%$ Indians suffered due to Covid-19 pandemic, finds MOTN survey. 7 August. Available at: https:// www.msn.com/en-in/money/topstories/income-of-63-india ns-suffered-due-to-Covid-19-pandemic-finds-motn-survey/ ar-BB17HhBi. Accessed 10 August 2020.

Topcu, M., and O. Gulal. 2020. The impact of Covid-19 on emerging stock markets. Finance Research Letters 36: 1-4.

Tseng, M.L. 2009. A causal and effect decision making model of service quality expectation using grey-fuzzy DEMATEL approach. Expert Systems with Applications 36 (4): 7738-7748.

Tzeng, G.H., C.H. Chiang, and C.W. Li. 2007. Evaluating intertwined effects in e-learning programs: A novel hybrid MCDM model based on factor analysis and DEMATEL. Expert Systems with Applications 32 (4): 1028-1044.

Vyas, M. 2020. Lockdown 2.0: unemployment rate touches $26 \%$ amid Covid-19 outbreak. Business Standard, 20 April. Available at: https://www.business-standard.com/article/opinion/ unemployment-rate-touches-26-per-cent-120042001081_1. html. Accessed 22 April, 2020.

Westerhoff, F. 2004. Greed, fear and stock market dynamics. Physica A: Statistical Mechanics and its Applications 343: 635-642.

WHO 2020. Rolling updates on corona virus disease. Available at: www.who.int/emergencies/diseases/novel-coronavirus-2019/ events-as-they-happen. Accessed 13 August 2020.

Wolfslehner, B., H. Vacik, and M.J. Lexer. 2005. Application of the analytic network process in multi-criteria analysis of sustainable forest management. Forest Ecology and Management 207 (1-2): 157-170.

Xia, X., and J. Ruan. 2020. Analyzing barriers for developing a sustainable circular economy in agriculture in China using greyDEMATEL approach. Sustainability 12 (16): 1-25.

Yang, T., and C.C. Hung. 2007. Multiple-attribute decision making methods for plant layout design problem. Robotics and Computer-Integrated Manufacturing 23 (1): 126-137. 
Yue, P., A. Gizem Korkmaz, and H. Zhou. 2020. Household financial decision making amidst the Covid-19 pandemic. Emerging Markets Finance and Trade 56 (10): 2363-2377.

Zhang, D., M. Hu, and Q. Ji. 2020. Financial markets under the global pandemic of Covid-19. Finance Research Letters 36: 1-6.

Publisher's Note Springer Nature remains neutral with regard to jurisdictional claims in published maps and institutional affiliations.

Ritika is pursuing Ph.D. from Indira Gandhi National Open University, New Delhi. She is currently a member of the Indian Commerce Association. She holds the degree of B.Com. (Hons.) and M.Com. from the University of Delhi. She has qualified UGC NET-JRF in both disciplines, Commerce and Management. She has published research papers in reputed journals indexed in UGC Care, Scopus, and ABDC list. She has presented papers at national and international conferences at institutions of national repute. Her research areas include Behavioral and corporate finance, risk analysis, and portfolio management.

Himanshu is an Assistant Professor based at the Department of Commerce, Government PG College, Bisauli, India. He is also a doctoral fellow at the Indian Institute of Technology, Roorkee, India. He holds the degree of M.Com. and B.Com. (Hons.) from the University of Delhi. He has qualified UGC NET-JRF in both disciplines, Commerce and Management. He is currently a member of the British Accounting \& Finance Association, American Accounting Association, and Indian Commerce Association. He has been a member of the Academy for Global Business Advancement. He has published research papers in reputed journals indexed in Scopus, Web of Science, and Australian Business Deans Council list. He is the reviewer of various ABDC listed journals. He has received the Best Paper Award in the International Conference organized by IBS Hyderabad. He has presented papers at national and international conferences at institutions of national repute (for instance, the British Accounting Association and the American Accounting Association associated conferences). His research areas include fair value reporting, financial management, earnings management, and accounting for managers.

Prof. Nawal Kishor is a Professor of Finance based at the School of Management Studies, IGNOU, New Delhi. He has been working at IGNOU for the last 30 years. He has been engaged in teaching, training, research, and other academic activities. He has published various research papers in reputed international and national journals. He has presented 15 research papers in international and national conferences. He has been actively involved as a Key note speaker, technical session chairperson, guest of honor, and resource person in international and national conferences. He had been the resource person for academic staff colleges of various universities as well as for the faculty development programmes. He has been the managing editor of The Indian Journal of Commerce. 